\title{
Applying active network management schemes to an irish distribution network for wind power maximisation
}

DOI:

10.1049/cp.2009.1052

Link to publication record in Manchester Research Explorer

\section{Citation for published version (APA):}

Ochoa, L. F., Keane, A., Dent, C., \& Harrison, G. P. (2009). Applying active network management schemes to an irish distribution network for wind power maximisation. In IET Conference Publications/IET Conf Publ https://doi.org/10.1049/cp.2009.1052

\section{Published in:}

IET Conference Publications|IET Conf Publ

\section{Citing this paper}

Please note that where the full-text provided on Manchester Research Explorer is the Author Accepted Manuscript or Proof version this may differ from the final Published version. If citing, it is advised that you check and use the publisher's definitive version.

\section{General rights}

Copyright and moral rights for the publications made accessible in the Research Explorer are retained by the authors and/or other copyright owners and it is a condition of accessing publications that users recognise and abide by the legal requirements associated with these rights.

\section{Takedown policy}

If you believe that this document breaches copyright please refer to the University of Manchester's Takedown Procedures [http://man.ac.uk/04Y6Bo] or contact uml.scholarlycommunications@manchester.ac.uk providing relevant details, so we can investigate your claim.

\section{OPEN ACCESS}




\section{APPLYING ACTIVE NETWORK MANAGEMENT SCHEMES TO AN IRISH DISTRIBUTION NETWORK FOR WIND POWER MAXIMISATION}

\author{
Luis F OCHOA \\ University of Edinburgh - UK \\ luis_ochoa@ieee.org \\ Chris DENT \\ University of Edinburgh - UK \\ chris.dent@ed.ac.uk
}

\author{
Andrew KEANE \\ University College Dublin - Ireland \\ andrew.keane@ucd.ie \\ Gareth P HARRISON \\ University of Edinburgh - UK \\ gareth.harrison@ed.ac.uk
}

\begin{abstract}
In order for governments worldwide to achieve their renewable targets, large amounts of new capacity, mainly wind power, need to be connected to power systems. A significant share is expected to be deployed at distribution levels. This paper is aimed at assessing the maximum wind power capacity a distribution network is able to integrate based on a multi-period AC Optimal Power Flow technique tailored to cater for Active Network Management schemes such as coordinated voltage control, adaptive power factor control and energy curtailment. The methodology is applied to an Irish $38 \mathrm{kV}$ circuit, considering the time-varying characteristics of demand and multiple wind generation profiles based on the coincident hours of different loading levels and wind power outputs over a year.
\end{abstract}

\section{INTRODUCTION}

Installed capacity of wind power generation in Ireland has increased almost sixfold in the last 5 years, reaching at the end of 2007 a total capacity of 805MW [1], a considerable amount of which is connected to distribution level in the form of Distributed Generation (DG). Further DG is expected to connect in the coming years resulting in increasing penetrations, the majority of which will be wind power owing to Ireland's rich wind resource along its Atlantic coastline.

Distribution Network Operators (DNOs) worldwide recognise the potential benefits brought about by DG [2], and, particularly, the environmental impact of renewable sources. However, DG presents DNOs with technical challenges $[2,3]$ that so far, due to the relatively low levels of penetration, have been addressed with the traditional passive approaches of limited sophistication. A number of new control methods have been proposed, which fall under the heading of Active Network Management (ANM) [4-7]. Active management of the network offers a means by which increasing penetrations of DG can be connected. These methods entail integrating the assets and participants through use of control and communication systems.

Previous work [8] demonstrated the ability of using Optimal Power Flow (OPF) to maximise generation capacity and, therefore, identify available headroom. Nonetheless, the technique only uses a single deterministic optimisation. In [9], a methodology based on sensitivity analysis and linear programming was developed to optimise the allocation of multiple-resource DG energy. However, while annual timeseries data for both demand and generation was employed to assess the optimality of the DG allocation, it was not directly integrated in the optimisation process.

Building on [10], a multi-period AC OPF-based technique is proposed to apply various ANM schemes in order to maximise wind power capacity in distribution networks. Coordinated voltage control, adaptive power factor control and energy curtailment are considered. The multi-period capabilities of the technique allow the time-varying characteristics of demand and generation to be taken into account, whereas voltage and thermal constraints will be kept within statutory limits. The methodology is applied to a Irish $38 \mathrm{kV}$ distribution circuit used in [9]. The distribution network is analysed considering the time-varying characteristics of demand and multiple wind generation profiles based on the coincident hours of different loading levels and wind power outputs over a year.

\section{METHODOLOGY}

The basic AC OPF formulation aimed at maximising the total DG capacity $P$ across $n$ generators (indexed by $g$ ) is

$$
\text { Maximise } \sum_{g=1}^{n} P_{g}
$$

This maximisation will be typically subject to Kirchhoff's Current Law (KCL), as well as the corresponding voltage and thermal limits, among other considerations (e.g. power exports to the transmission grid). In order to incorporate Active Network Management schemes, the parameters and variables involved should be adapted, and new constraints created. Fig 1 shows how the considerations for the basic $\mathrm{OPF}$ are extended to cater for the ANM schemes taken into account in this work.

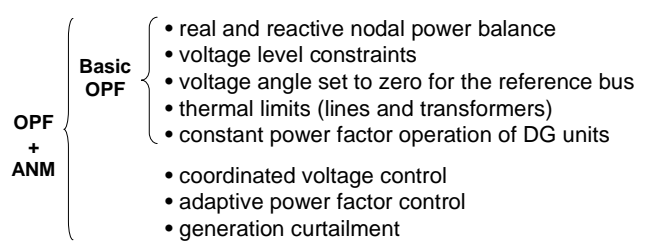

Fig 1. Basic and extended constraints for the proposed OPF formulation. 
Coincident hours of different loading levels and wind power outputs based on half-hourly values over a year will maintain the time-varying characteristics of the demand and wind generation. Thus3, the multi-periodicity is achieved by relating each demand-generation combination to its time duration (number of coincident hours). In this way, each period has a different set of power flow variables whereas a unique (inter-period) set of generation capacity variables is used throughout the analysis in order to create the multiperiod interdependency. This is shown schematically in Fig 2.

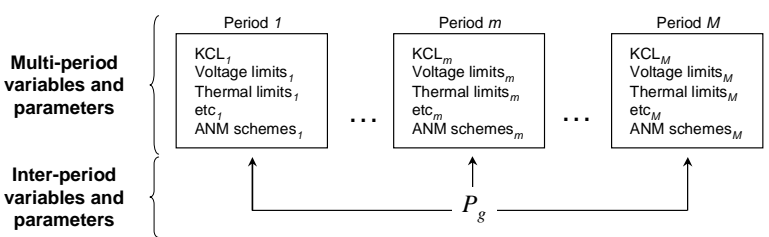

Fig 2. Multi-period interdependency.

As mentioned previously, the variables, parameters and constraints of the basic OPF must be adapted according to the necessities of each ANM scheme. The following subsections describe some of the considerations.

\section{Coordinated Voltage Control}

Due to the varying nature of demand, on-load tap changers (OLTCs) are commonly used in distribution substations in order to maintain voltages within mandatory limits. Nonetheless, depending on the network characteristics, integrated coordination of the OLTC might allow more DG capacity to be connected [11]. Thus, the voltage at the substation (targeted by the OLTC) will be treated as a multiperiod variable, rather than a fixed parameter, while maintaining the resulting value within the statutory range.

\section{Adaptive Power Factor Control}

Depending on the technology utilised by the distributed generator, the operation in leading (capacitive behaviour), unity or lagging power factors is feasible. In this work, it is envisaged that DG units provide a scheme by allowing dispatch of their power factor. Thus, the power angle of each generator will be considered as a multi-period variable, while operating power factors within a given range $(0.95$ lagging/leading).

\section{Energy Curtailment}

Large volumes of wind power capacity can potentially lead to voltage rise at times of minimum demand. Also, as it is the case of rural areas weakly connected to the main grid, power transfer capacities could be binding [6]. An option to ease these problems is the curtailment of the power output $[6,11,12]$. For this purpose, real power curtailment is formulated as negative generation (or positive demand) that counteracts each DG unit. Moreover, given the economic aspects of lost wind power production, the total amount of curtailed energy will be also restricted to a percentage of the total energy that otherwise would have been delivered through each DG connection.

The method was coded in the AIMMS optimisation modelling environment [13] using the nonlinear programming solver CONOPT 3.14A.

\section{CASE STUDY}

\section{$38 \mathrm{kV}$ Irish Network}

The one-line diagram of a typical rural section of the Irish $38 \mathrm{kV}$ distribution network is shown in Fig 1. Corresponding line data is included in Table 1 . The feeders are supplied by one 31.5MVA 110/38kV transformer. Grid Supply Point (GSP) voltage is assumed to be nominal. In the original configuration (no DG), the OLTC at the substation has a target voltage of $1.078 \mathrm{pu}(41 \mathrm{kV})$ at the busbar. Voltage limits are taken to be $+10 /-6 \%$ of nominal. The maximum demand of the network is $15.12 \mathrm{MW}$.

Three potential wind power locations are considered to be connected to the remote nodes where two different prolific wind resources exist.

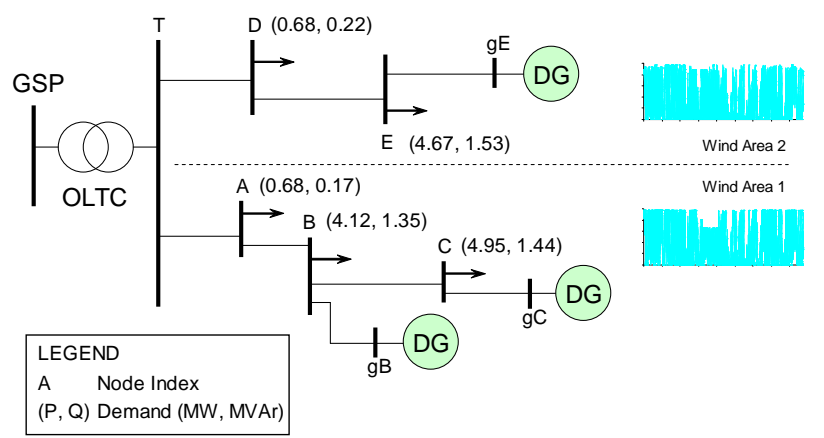

Fig 3. $38 \mathrm{kV}$ 5-bus network one-line diagram during maximum load conditions. Three potential distributed wind power generation sites are considered. Two different wind areas are adopted.

\begin{tabular}{|c|c|c|c|c|c|c|c|}
\hline Line & $\mathbf{R}$ & $\mathrm{X}$ & Smax & Line & $\mathbf{R}$ & $X$ & Smax \\
\hline GSP - T & - & 0.2500 & 0.3150 & $C-g C$ & 0.1292 & 0.1357 & 0.1975 \\
\hline $\mathrm{T}-\mathrm{A}$ & 0.0296 & 0.0863 & 0.3817 & $T-D$ & 1.1260 & 1.1930 & 0.3817 \\
\hline$A-B$ & 0.5941 & 0.6244 & 0.1975 & $D-E$ & 0.1550 & 0.1629 & 0.1975 \\
\hline$B-C$ & 0.3875 & 0.4072 & 0.1975 & $E-g E$ & 0.1292 & 0.1357 & 0.1975 \\
\hline$B-g B$ & 0.1292 & 0.1357 & 0.1975 & & & & \\
\hline
\end{tabular}

Table 1. Line and transformer parameters (resistance, reactance and maximum complex power flow) for the $38 \mathrm{kV} 5$-bus network. All values in per unit (100MVA base).

\section{Coincident Hours}

Half-hourly demand and potential wind power generation (Wind Area 1, Fig. 3) are presented in Fig. 4. In order to reduce the computational burden for the multi-period analysis, a number of clusters (different combinations of demand and generation levels) are defined and the corresponding duration calculated. Fig. 5 presents the coincident hours for each of the adopted periods, taking into account 10 ranges for demand, and 11 ranges for generation (including nil power output), thus effectively reducing the number of periods to 77 (Fig. 5, Right).

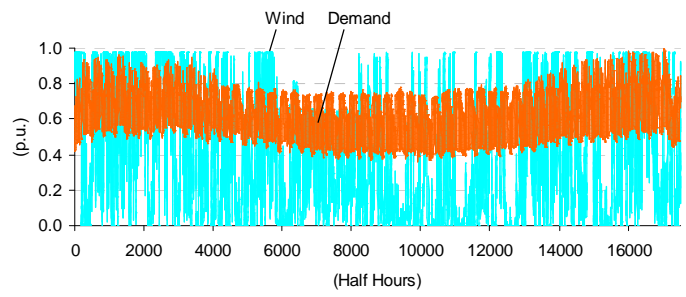

Fig 4. Half-hourly demand and wind power data (Wind Area 1). 


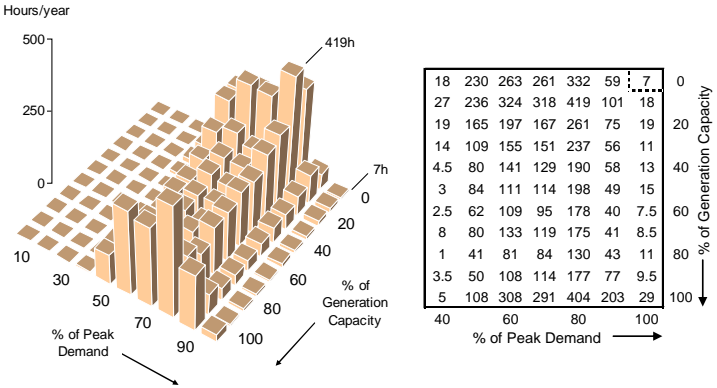

Fig 5. Coincident hours for each of the adopted demand-generation periods considering only Wind Area 1.

The second wind profile (Wind Area 2) requires the periods to be re-assessed since the previous coincident hours are no longer valid. As shown in Fig. 6 (Left), for each range of generation capacity of the first wind profile, a 'layer' with the coincident hours of demand-generation is created for the second wind power profile. Although this approach may seem to create a large number of periods, due to the geographical relation of the wind data used here, only 139 are effectively considered. Fig. 6 (Right) presents the coincident hours for these periods.

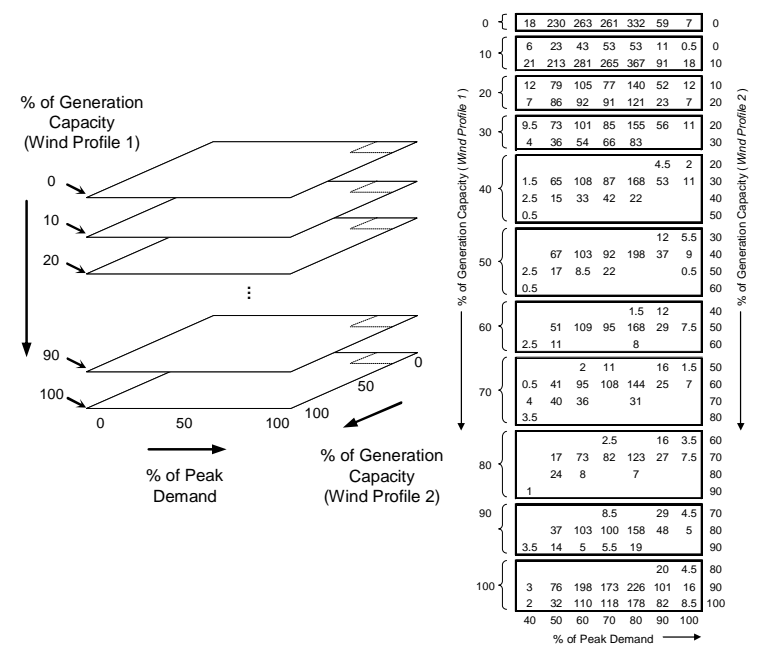

Fig 6. Schematic example of how the coincident hours are obtained for two wind profiles (Left). Coincident hours for each of the periods to be considered in the analyses of the 5-bus network (Right).

\section{Results}

A simple initial evaluation of the network's ability to connect new generation capacity would be to consider nonintermittent DG during maximum demand. In this scenario, the coordinated voltage control (CVC) and adaptive power factor control $(\mathrm{PFc}) \mathrm{ANM}$ schemes will be studied. The (single-period) OPF-based optimal DG capacity and the corresponding maximum capacity usage considering the implementation of CVC of the OLTC, as well as different power factor settings, are presented in Fig. 7.

Clearly, during peak conditions, the network is capable of being a net exporter of power since total DG capacities surpass local demand. Significant gains are achieved when coordinated voltage control is in place. It can also be seen that adequate settings of the fixed power factors allows further generation capacity. However, it is the combination of $\mathrm{CVC}$ and $\mathrm{PFc}$ that produces the largest total DG capacity. In terms of maximum capacity usage, as expected, the methodology aims to make the best use of the thermal capacities of the lines and transformers (Fig 7, Right). Due to the adopted potential locations for DG, it is the connection line E-gE, line A-B, and the transformer which most of the time constrain further DG generation capacity.
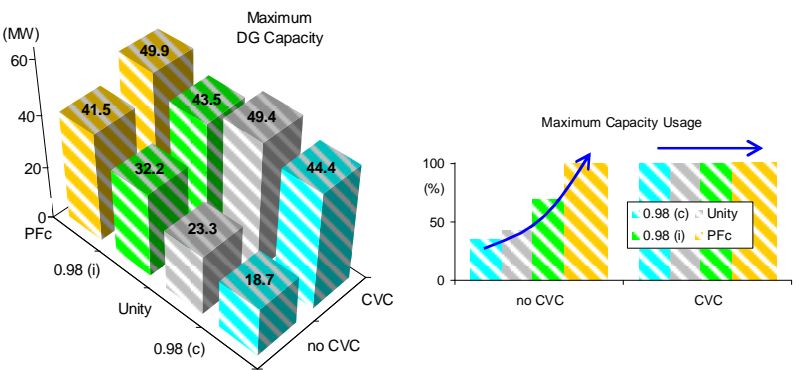

Fig 7. Maximum demand and non-intermittent generation: (Left) Maximum DG capacity and corresponding (Right) maximum capacity usage applying different voltage control strategies and power factor settings. (c: capacitive, i: inductive, and PFc: adaptive power factor control).

Although the maximum demand analysis provides an idea of the non-intermittent capacity that might be connected to a given network, it is the combination of lower demand levels and different generation power outputs (intermittent DG) that constrain the capacity of new developments. Using the coincident hours from Fig. 6, the annual units delivered (demand) and units lost (losses) for the $38 \mathrm{kV} 5$-bus network amount to $92.8 \mathrm{GWh}$ and $4.6 \mathrm{GWh}$, respectively. Units lost, as a percentage of units delivered, are $5 \%$.

The maximum wind power capacity that can be connected to the network was investigated considering the cases presented in Fig. 7, plus two levels of energy curtailment: 2 and 5\%. The corresponding results are shown in Fig. 8 (Left). When curtailment is not considered, the variability of both the demand and wind leads to significantly different (smaller) DG capacities than those calculated for peak demand and non-intermittent generation (Fig. 7). Particularly, coordinated voltage control allows on average three times more capacity than with fixed power factor operation. Adaptive power factor control also benefits from CVC, with an increase in capacity of $34 \%$.

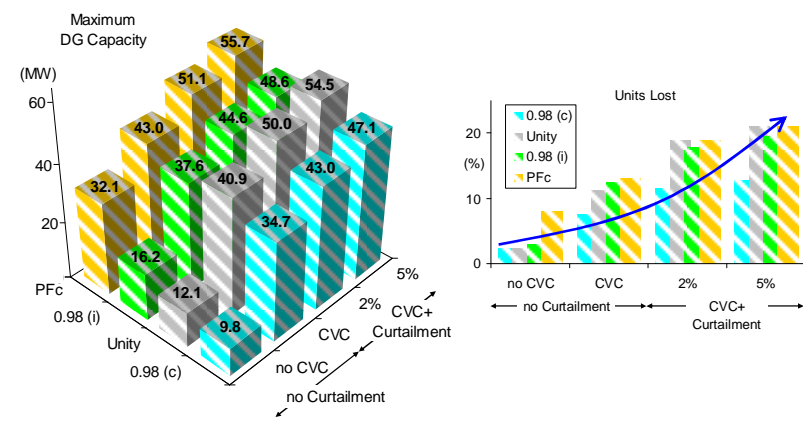

Fig 8. Time-varying demand and generation: Maximum DG capacity considering voltage control strategies, power factor settings and curtailment limits (Left), and the corresponding percentage of units lost (Right). 
Furthermore, with CVC and PFc in place, a $2 \%$ limit of energy curtailment increases by $18 \%$ the wind power capacity. This figures goes up to $30 \%$ when the curtailment limit is set to $5 \%$. Nonetheless, it is important to note that, for this specific network, unity power factor allows similar amounts of capacity (average of 3\% less) to those obtained with PFc when combined with CVC. Consequently, fixed power factor settings could represent a potential solution that avoids the investment involved with the PFc scheme.

When power is exported to the transmission grid, higher levels of energy losses might also be produced. Fig. 8 (Right) shows the annual energy losses (units lost) for each case as percentage of units delivered (demand). In all the cases where at least one ANM scheme is in place, units lost considerably surpassed the 5\% mark of the original 5-bus network. In a regulatory framework where DNOs have annual loss targets that are relatively close to their historic performances, exceeding such levels could mean economic penalties that the DNO will have to bear. On the other hand, optimal capacities found without considering ANM schemes resulted in losses below the $5 \%$ mark, potentially granting the DNO with economic incentives. It is also worthwhile to bear in mind that wind power offsets energy supplied by the transmission grid, i.e., conventional plants, and therefore the corresponding environmental benefits should also be adequately quantified.

\section{CONCLUSIONS}

Given the inherent constraints for new developments, such as planning permission, and land and resource availability, DNOs need to assess the extent to which their networks are capable of connecting new generation. In this context, innovative control strategies, i.e., Active Network Management, will play an important role. The OPF-based technique presented here is potentially useful for distribution planning, where time-varying characteristics of demand and generation (including multiple resources) are also taken into account. The use of ANM schemes clearly presents several technical benefits that allow the integration of further generation capacity to distribution networks. It is important, however, that each ANM solution, or the combination of them, should be assessed on a case-by-case basis since network characteristics drive the performance (e.g., losses) and cost-effectiveness of each scheme. Power curtailment proved to have a significant impact on connecting larger volumes of DG, however its actual implementation will also depend on commercial negotiations.

\section{ACKNOWLEDGMENTS}

This work is part-funded through the EPSRC Supergen V, UK Energy Infrastructure (AMPerES) grant in collaboration with UK electricity network operators working under Ofgem's Innovation Funding Incentive scheme - full details on http://www.supergen-amperes.org/. A. Keane is funded under the Charles Parsons Energy Research Awards.

\section{REFERENCES}

[1] EWEA - European Wind Energy Association. (2006, Oct.). European record for wind power: over 6,000 MW installed in 2005. Wind energy has surpassed EC White Paper targets for 2010. [Online]. Available: http://www.ewea.org/fileadmin/ewea_documents/docu ments/press_releases/2006/060201_Statistics_2005.pd $\mathrm{f}$

[2] N. Jenkins, R. Allan, P. Crossley, D. Kirschen, and G. Strbac, 2000, Embedded generation, Institution of Electrical Engineers, London.

[3] P.P. Barker and R.W. De Mello, 2000, "Determining the impact of distributed generation on power systems: part 1 - radial distribution systems", Proceedings IEEE Power Engineering Society Summer Meeting, 1645-1656.

[4] A. Shafiu, T. Bopp, I. Chilvers, G. Strbac, N. Jenkins, and $\mathrm{H}$. Li, 2004, "Active management and protection of distribution networks with distributed generation", Proceedings IEEE Power Engineering Society General Meeting, vol. 1, 1098-1103.

[5] G.W. Ault, R.A.F. Currie, and J.R. McDonald, 2006, "Active power flow management solutions for maximising DG connection capacity", Proceedings IEEE Power Engineering Society General Meeting, 5.

[6] R.A.F. Currie, G.W. Ault, R.W. Fordyce, D.F. MacLeman, M. Smith, and J.R. McDonald, 2008, "Actively managing wind farm power output", IEEE Trans. on Power Systems. vol. 23, 1523-1524.

[7] J.R. McDonald, 2008, "Adaptive intelligent power systems: Active distribution networks", Energy Policy. vol. 36, 4346-4351.

[8] G.P. Harrison and A.R. Wallace, 2005, "Optimal power flow evaluation of distribution network capacity for the connection of distributed generation", IEE Proceedings Generation, Transmission \& Distribution. vol. 152, 115-122.

[9] A. Keane and M. O'Malley, 2007, "Optimal utilization of distribution networks for energy harvesting", IEEE Trans. on Power Systems. vol. 22, 467-475.

[10] L.F. Ochoa, C.J. Dent, and G.P. Harrison, 2008, "Maximisation of intermittent distributed generation in active networks", Proceedings CIRED Seminar 2008: SmartGrids for Distribution, 4.

[11] S.N. Liew and G. Strbac, 2002, "Maximising penetration of wind generation in existing distribution networks", IEE Proceedings Generation, Transmission \& Distribution. vol. 149, 256-262.

[12] B. Fox, D. Flynn, L. Bryans, N. Jenkins, D. Milborrow, M. O'Malley, R. Watson, and O. AnayaLara, 2007, Wind power integration: Connection and system operational aspects, IET.

[13] J. Bisschop and M. Roelofs, "AIMMS - The user's guide," Paragon Decision Technology, 2006. 